\title{
Redox factor-1: an extra-nuclear role in the regulation of endothelial oxidative stress and apoptosis
}

\author{
P Angkeow ${ }^{1,3}$, SS Deshpande ${ }^{1,3}$, B Qi ${ }^{1}$, Y-X Liu ${ }^{1}$, YC Park ${ }^{1}$, \\ BH Jeon ${ }^{1}$, M Ozaki ${ }^{2}$ and $\mathrm{K}$ Irani $^{*, 1}$ \\ ${ }^{1}$ Division of Cardiology, Department of Medicine, The Johns Hopkins University \\ School of Medicine, Baltimore, MD, USA \\ 2 Department of Experimental Surgery and Bioengineering, National Children's \\ Hospital, Tokyo, Japan \\ ${ }^{3}$ These authors contributed equally to this work \\ * Corresponding author: K Irani, Division of Cardiology, Department of \\ Medicine, The Johns Hopkins University School of Medicine, Ross 1023, 720 \\ Rutland Ave., Baltimore MD 21205, USA. \\ Tel: (410) 502 6902; Fax: (410) 955 3478; E-mail: kirani@jhmi.edu
}

Received 6.8.01; revised 5.1.02; accepted 12.1.02

Edited by B Osborne

\begin{abstract}
The rac1 GTPase promotes oxidative stress through reactive oxygen species (ROS) production, whereas the DNA repair enzyme and transcriptional regulator redox factor-1 (ref-1) protects against cell death due to oxidative stimuli. However, the function of ref-1 in regulating intracellular oxidative stress, particularly that induced by rac1, has not been defined. We examined the role of ref- 1 in vascular endothelial cell oxidative stress and apoptosis. Ref-1 was expressed in both the cytoplasm and nuclei of resting endothelial cells. Cytoplasmic ref-1 translocated to the nucleus with the oxidative trigger hypoxia/reoxygenation (H/R). Forced cytoplasmic overexpression of ref- 1 suppressed $\mathrm{H} / \mathrm{R}$-induced oxidative stress $\left(\mathrm{H}_{2} \mathrm{O}_{2}\right.$ production), $\mathrm{NF}-\kappa \mathrm{B}$ activation, and apoptosis, and also mitigated rac1-regulated $\mathrm{H}_{2} \mathrm{O}_{2}$ production and NF- $\kappa$ B transcriptional activity. We conclude that inhibition of oxidative stress is another mechanism by which ref-1 protects against apoptosis, and that this is achieved through modulation of cytoplasmic rac1-regulated ROS generation. This suggests a novel extra-nuclear function of ref-1.

Cell Death and Differentiation (2002) 9, 717-725. doi:10.1038/ sj.cdd. 4401025
\end{abstract}

Keywords: redox factor-1 (ref-1); rac1; reactive oxygen species (ROS); NAD(P)H oxidase; hypoxia/reoxygenation (H/R)

Abbreviations: HUVECs, human umbilical vein endothelial cells; $\mathrm{H} / \mathrm{R}$, hypoxia/reoxygenation; NF-KB, nuclear factor-kappa B; ROS, reactive oxygen species; ref-1, redox factor-1; redox, reductionoxidation

\section{Introduction}

Exposure of cells or tissue to oxidative stimuli such as hypoxia/reoxygenation $(H / R)$, ischemia/reperfusion $(I / R)$, and inflammatory cytokines induces the generation of reactive oxygen species (ROS) resulting in alterations in intracellular reduction/oxidation (redox) state. Cellular redox changes can have profound effects on the activities of transcription factors, and such regulation of transcriptional activation has emerged as one of the important mechanisms that prokaryotic and eukaryotic cells employ for the expression of specific genes important in inflammation, death and survival. ${ }^{1}$

Stimuli that result in oxidative stress employ a number of cellular ROS generating systems. Among these is the $\mathrm{NAD}(\mathrm{P}) \mathrm{H}$ oxidase regulated by the ubiquitous small GTPase rac1. Many components of the phagocyte NADPH oxidase are expressed in non-pahgocytic cells, including cardiovascular cell types. ${ }^{2}$ The functional significance of this oxidase is evident by the fact that rac1-regulates the production of ROS in a variety of cell types in response to a many oxidative stimuli such as tumor necrosis factor (TNF) ${ }^{3}$ and H/R. ${ }^{4}$

Redox factor-1 (ref-1) is a ubiquitous $37 \mathrm{kD}$ bi-functional protein. Ref-1 stimulates the DNA binding activities of the AP-1 family of transcription factors by a redox-dependent mechanism. ${ }^{5,6}$ This effect is mediated through reduction of a conserved cysteine residue located at the DNA-binding domains of c-fos and c-jun. ${ }^{7}$ Through a similar reducing action, ref- 1 is also capable of modulating or activating other classes of transcription factors that regulate cell growth, differentiation, survival, and death including NF- $\kappa \mathrm{B}$, p53, Egr-1, c-Myb, HLF, and Pax-8..$^{6,8-12}$ Ref-1 also has DNA repair activity. It is an apurinic/apyrimidinic endonuclease (APE), an important enzyme in the base excision repair (BER) pathway. ${ }^{13}$ Apurinic/Apyrimidinic (AP) damage of DNA occurs with diverse oxidative stimuli, is highly mutagenic, and AP repair is indispensable for the genomic integrity and viability of cells. Although the DNA repair and transcription factor reducing properties of ref-1 are well known, other fundamental mechanisms via which it may regulate redox-sensitive transcription, and influence cell death are yet to be elucidated.

Ref-1 has been implicated in protection against cell death resulting from oxidative stimuli. Depletion of ref- 1 renders cells more sensitive to hyperoxia, ${ }^{14}$ and a decrease in ref- 1 expression is associated with apoptosis in ischemic neuronal tissue. ${ }^{15}$ However, the role of ref- 1 and the cellular phenotypes that it regulates in cardiovascular tissue is not known. The vascular endothelium is the first line of defense against a variety of oxidative stimuli, and redoxregulated activation and death of endothelial cells have been implicated in the pathogenesis of vascular disorders. We therefore investigated the role of ref- 1 in regulating the response of vascular endothelial cells to the oxidative stimulus hypoxia/reoxygenation $(H / R)$.

Here, we report that ref- 1 protects endothelial cells from apoptosis, and prevents endothelial cell activation of the inflammatory transcription factor $N F-\kappa B$ in response to $H / R$ through a novel mechanism of action: suppression of intracellular $\mathrm{H}_{2} \mathrm{O}_{2}$ regulated by the small GTPase rac1. 
Although our experiments are limited to endothelial cells, the ubiquitous expression of ref- 1 and rac1, and their importance in the regulation and response of cells to oxidative stimuli, suggests that the functional interaction between these two proteins described herein may also be relevant to the redox biology of other cell types.

\section{Results}

\section{Expression of ref-1 in the cytoplasm and nucleus of endothelial cells: translocation to the nucleus with H/R}

We first determined the sub-cellular expression pattern of ref1 under basal normoxic conditions, and after hypoxia/ reoxygenation $(H / R)$ (Figure $1 A, B)$. Under normoxic conditions, endogenous ref- 1 was present in both the cytoplasm and nuclei of uninfected endothelial cells, and cells infected with the control $\mathrm{Ad} \beta \mathrm{g}$ al virus. Hypoxia/reoxygenation $(\mathrm{H} / \mathrm{R})$ of uninfected, and $\mathrm{Ad} \beta \mathrm{g}$ al-infected cells led to a significant increase in nuclear/cytoplasmic ref-1. H/R or hypoxia alone for $6 \mathrm{~h}$ resulted in no significant change in total expression of ref-1 (not shown).

\section{Adenovirus-mediated cytoplasmic and nuclear overexpression of ref- 1}

With the goal of examining the role of ref- 1 in oxidative stress and apoptosis, we used a recombinant adenovirus encoding full-length ref-1, Adref-1, to overexpress ref-1 in endothelial cells. Adenoviral vectors are capable of gene transfer efficiencies approaching $100 \%$ in HUVECs. ${ }^{3}$ Infection of HUVECs with Adref- 1 resulted in significant, and dosedependent overexpression of ref-1 compared to cells infected with Ad $\beta$ gal (Figure 1B,C). Importantly, infection with Adref-1 led to an increase in both cytoplasmic and nuclear expression of ref-1 (Figure $1 \mathrm{C}$ ). Moreover, when compared to $\mathrm{Ad} \beta \mathrm{gal}-$ infected cells, Adref-1-infected cells showed significantly higher cytoplasmic ref-1 expression even after H/R (Figure $1 \mathrm{~B})$. This demonstrates that infection with Adref- 1 is able to significantly increase both cytoplasmic and nuclear ref-1 expression during normoxic conditions and after the $H / R$ stimulus.

\section{Overexpression of ref-1 suppresses H/R-induced apoptosis}

Apoptosis plays an important part in post-hypoxic or postischemic cell death and tissue injury. ${ }^{16,17}$ We therefore investigated the role of ref-1 in programmed death of endothelial cells induced by $H / R$ (Figure 2A,B). Both uninfected and $A d \beta$ gal-infected cells were susceptible to $\mathrm{H} /$ $\mathrm{R}$-induced apoptosis. This reoxygenation-stimulated apoptosis was suppressed in Adref-1-infected cells in a dosedependent fashion.

Oxidative stress is an important contributor to reoxygenation or reperfusion-induced apoptosis. ${ }^{16,18,19}$ Therefore, one mechanism for the above-cited effect could be a change in the cellular anti-oxidant capacity induced by ref1. To explore this possibility we examined the susceptibility

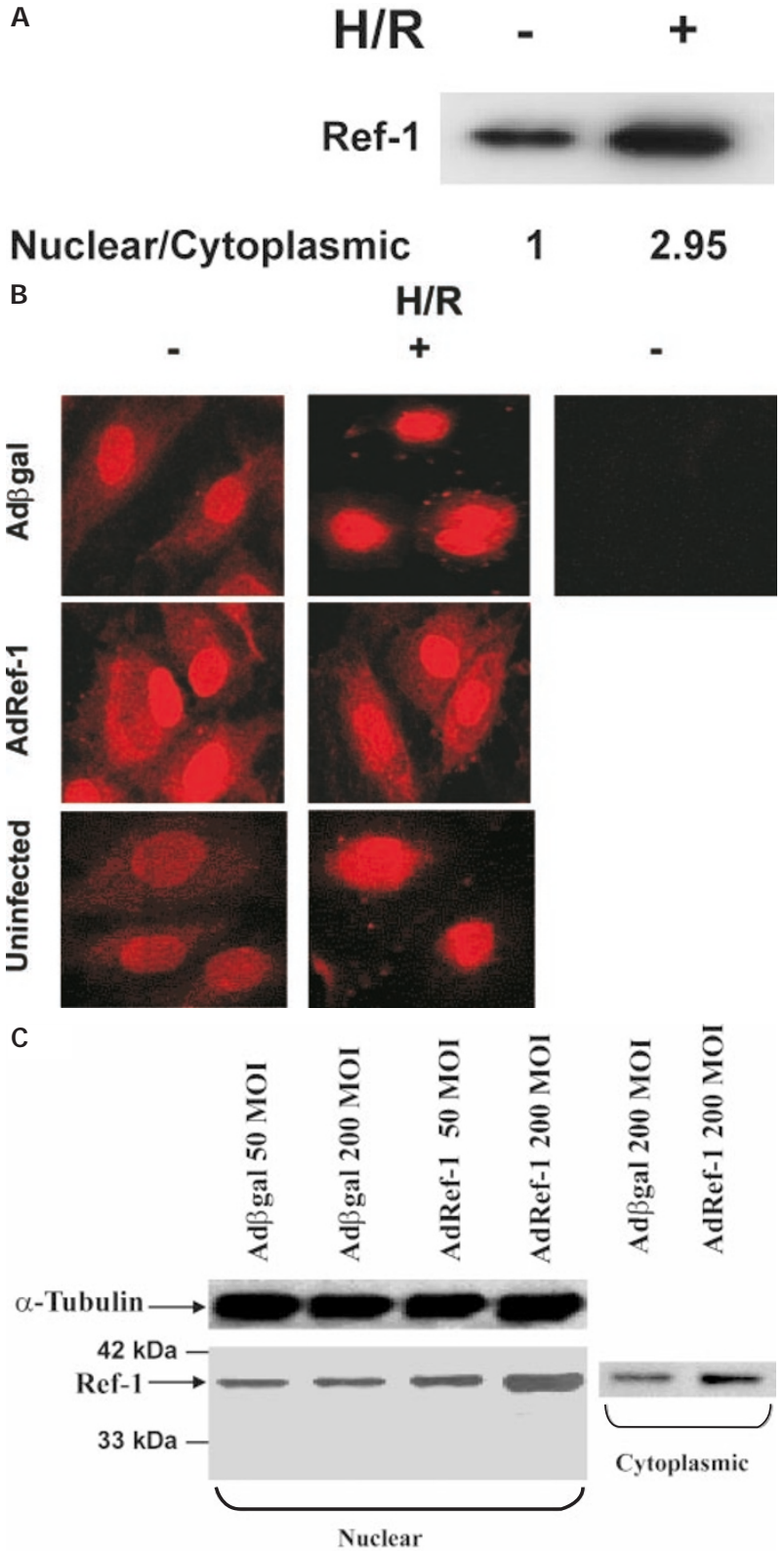

Figure 1 Basal and adenoviral-induced endothelial ref-1 expression and sub-cellular distribution during normoxia and with hypoxia/reoxgenation $(H / R)$. (A) Western blot for ref-1 in nuclear fractions of endothelial cells under normoxic conditions, and after hypoxia $6 \mathrm{~h} /$ reoxygenation $2 \mathrm{~h}$. Nuclear/ cytoplasmic ratio is calculated after normalization for protein loading. (B) Immunostaining for ref-1 in uninfected, $\mathrm{Ad} \beta \mathrm{gal}$ - and Adref-1-infected cells, with and without H/R. Viruses used at $200 \mathrm{MOI}$, hypoxia $6 \mathrm{~h}$, and reoxygenation $2 \mathrm{~h}$. - ref- $1 \mathrm{Ab}$ indicates omission of primary ref-1 antibody, but inclusion of secondary antibody. (C) Western blot for ref-1 in cytoplasmic and nuclear fractions of cells infected with $\mathrm{Ad} \beta \mathrm{g}$ gal and Adref-1. Protein loading of nuclear and cytoplasmic fractions is not comparable

of ref-1 overexpressing cells to $\mathrm{H}_{2} \mathrm{O}_{2}$-induced apoptosis, and compared it to cells infected with $\mathrm{Ad} \beta$ gal (Figure $2 \mathrm{C}$ ). A modest dose $(100 \mu \mathrm{M})$ of $\mathrm{H}_{2} \mathrm{O}_{2}$ was used so as not to overwhelm the cell's anti-oxidant capacities. Forced overexpression of ref- 1 did not protect against $\mathrm{H}_{2} \mathrm{O}_{2}$-induced apoptosis when compared to $\mathrm{Ad} \beta$ gal-infected cells. Thus 


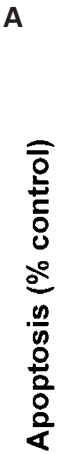

300

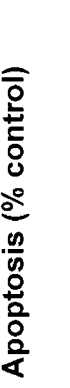

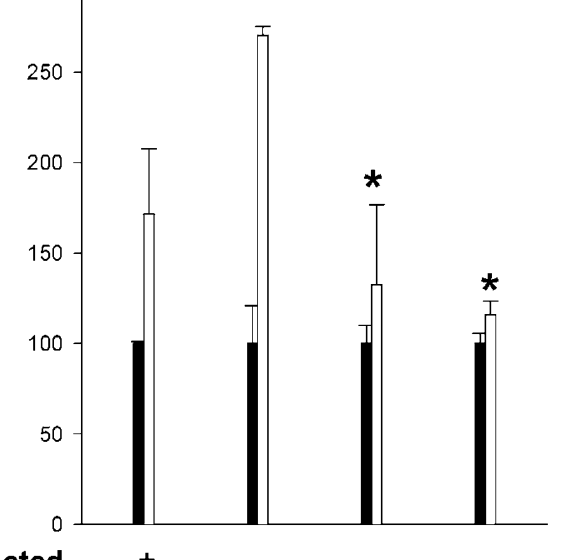

200

Uninfected Ad $\beta$ gal (MOI) AdRef-1 (MOI)

Normoxia $H / R$

B

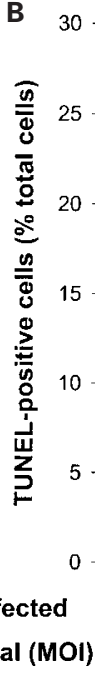

Adßgal (MOI)

AdRef-1 (MOI)

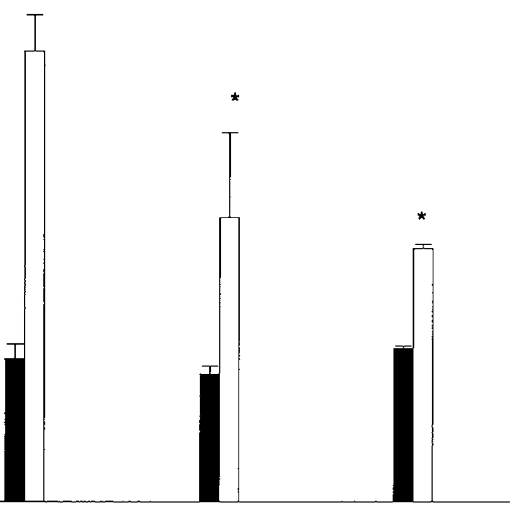

200
$50 \quad 200$

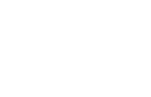

Normoxia

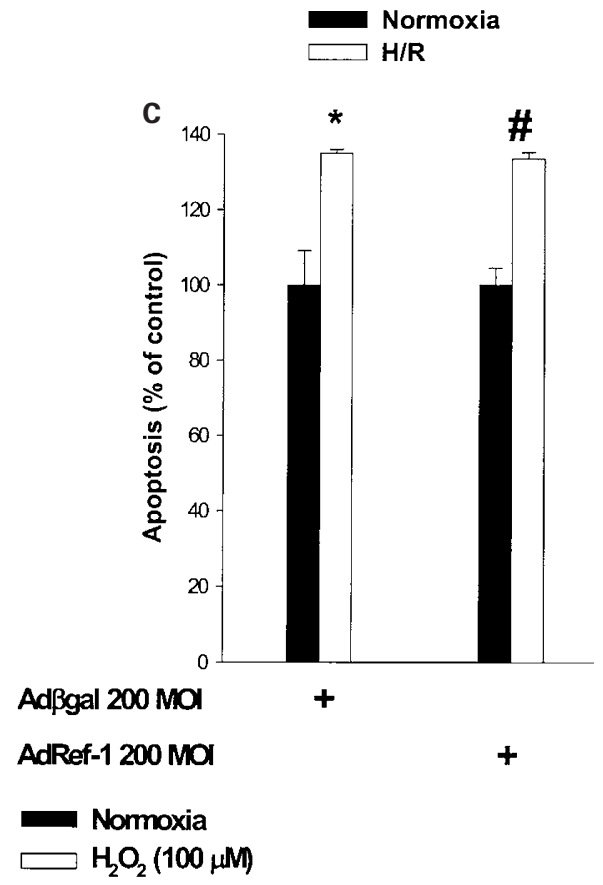

Figure 2 Ref-1 suppresses H/R-induced apoptosis. (A) Quantification of cell death (ELISA for cytoplasmic histone-DNA fragments) in uninfected, Ad $\beta$ gal-, and Adref-1-infected cells under normoxia and with $H / R$. Values are expressed as percent apoptosis compared to normoxic cells. Hypoxia $6 \mathrm{~h}$, reoxygenation $16 \mathrm{~h}$ ${ }^{*} P<0.05$ compared with Ad $\beta$ gal. (B) Quantification of apoptosis by TUNEL staining in uninfected, Ad $\beta$ gal-, and Adref-1-infected cells under normoxia and with $\mathrm{H} / \mathrm{R}$. ${ }^{*} P<0.05$ compared with Ad $\beta$ gal. (C) Quantification by ELISA of apoptosis induced by exogenous $\mathrm{H}_{2} \mathrm{O}_{2}$ in $\mathrm{Ad} \beta \mathrm{gal}$, and Adref-1-infected. cells. Values are expressed as per cent apoptosis in the absence of $\mathrm{H}_{2} \mathrm{O}_{2} .{ }^{*} P<0.05$ compared with $\mathrm{Ad} \beta$ gal without $\mathrm{H}_{2} \mathrm{O}_{2}$. $\# P=\mathrm{NS}$ compared with $\mathrm{Ad} \beta \mathrm{gal}+\mathrm{H}_{2} \mathrm{O}_{2}$. The figures are representative of two separate experiments

ref-1 does not protect cells from apoptosis resulting from a direct increase in intracellular oxidative stress through addition of exogenous $\mathrm{H}_{2} \mathrm{O}_{2}$. This suggests that ref- 1 does not affect $\mathrm{H}_{2} \mathrm{O}_{2}$ elimination by increasing the expression of cellular anti-oxidant defenses against $\mathrm{H}_{2} \mathrm{O}_{2}$ such as catalase and glutathione peroxidase, but rather protects against $\mathrm{H} / \mathrm{R}$-induced apoptosis through suppression of intracellular $\mathrm{H}_{2} \mathrm{O}_{2}$ production.

\section{Ref-1 inhibits H/R and TNF-induced oxidative stress}

Our next goal was to further explore the mechanism behind ref-1's ability to protect against post-hypoxic death. Therefore, we examined the role of ref- 1 in regulating the increase in intracellular oxidative stress in response to $H / R$ (Figure $3 A$ ). There was no significant difference in intracellular $\mathrm{H}_{2} \mathrm{O}_{2}$ levels 
between uninfected, Ad $\beta$ gal-infected, and Adref-1-infected cells under basal normoxic conditions. $H / R$ resulted in a marked increase in intracellular $\mathrm{H}_{2} \mathrm{O}_{2}$ in $\mathrm{Ad} \beta$ gal-infected cells. In comparison, cells infected with Adref- 1 showed significant reductions in $\mathrm{H} / \mathrm{R}$-stimulated intracellular $\mathrm{H}_{2} \mathrm{O}_{2}$ levels. This demonstrates that overexpression of ref- 1 in endothelial cells suppresses $\mathrm{H} / \mathrm{R}$-induced intracellular oxidative stress.

Next, we determined whether ref-1's ability to suppress the rise in intracellular $\mathrm{H}_{2} \mathrm{O}_{2}$ was stimulus-specific. To this end, we examined the effect of ref-1 overexpression on tumor necrosis factor- $\alpha$ (TNF)-induced oxidative stress (Figure 3A). In $\mathrm{Ad} \beta$ gal-infected cells TNF resulted in a predictable increase in intracellular $\mathrm{H}_{2} \mathrm{O}_{2}$ levels. In comparison, cells infected with Adref- 1 demonstrated a significant reduction in TNF-induced rise in $\mathrm{H}_{2} \mathrm{O}_{2}$. Thus, ref-1 inhibits a mechanism that leads to an increase in oxidative stress shared by both $H / R$, and TNF.

Since overexpression of ref-1 did not protect against apoptosis induced by addition of exogenous $\mathrm{H}_{2} \mathrm{O}_{2}$, we also determined whether ref- 1 had any effect on the elimination of intracellular $\mathrm{H}_{2} \mathrm{O}_{2}$ (Figure 3B). Addition of exogenous $\mathrm{H}_{2} \mathrm{O}_{2}$ resulted in a dose-dependent increase in intracellular peroxide in control $\mathrm{Ad} \beta \mathrm{gal}$-infected cells. Overexpression of ref-1 did not suppress this rise in intracellular $\mathrm{H}_{2} \mathrm{O}_{2}$. This further suggests that ref-1 suppresses $\mathrm{H} / \mathrm{R}$-induced increase in intracellular $\mathrm{H}_{2} \mathrm{O}_{2}$ by decreasing production, and not by altering the cell's capacity to eliminate peroxide.

Both TNF and H/R activate an intracellular oxidase regulated by the ubiquitous small GTPase rac1.,20 All the components of this multi-molecular $\mathrm{NAD}(\mathrm{P}) \mathrm{H}$ oxidase are expressed in vascular endothelial cells. ${ }^{2}$ We therefore determined the role of ref- 1 in regulating the production of $\mathrm{H}_{2} \mathrm{O}_{2}$ by rac1 (Figure $3 \mathrm{C}$ ). To accomplish this we coinfected cells with Adref-1 and Adrac1V12, an adenovirus encoding the activated allele of rac1. Co-infection with the two viruses resulted in co-expression of ref-1 and rac1V12. Expression of rac1V12 led to an increase in steady state intracellular $\mathrm{H}_{2} \mathrm{O}_{2}$ levels that was partly mitigated by overexpression of ref-1. This shows that overexpression of ref-1 suppresses rac1V12-stimulated oxidative stress.

\section{Ref-1 overexpression suppresses H/R-induced, rac1-regulated NF- $\kappa$ B activation}

The transcription factor nuclear factor-kappa $\mathrm{B}(\mathrm{NF}-\kappa \mathrm{B})$ is activated in response to oxidative stimuli in general, ${ }^{21}$ and $H / R$ or $\mathrm{l} / \mathrm{R}$ in particular. $^{22-24} \mathrm{NF}-\kappa \mathrm{B}$ activation has been implicated in a variety of inflammatory conditions including vascular inflammation seen with reperfusion injury. ${ }^{25}$ We therefore examined the effect of ref-1 overexpression on NF- $\kappa$ B activity (Figure $4 \mathrm{~A}$ ). H/R led to an approximately threefold induction of NF- $\kappa$ B transcriptional activity in both uninfected and $\mathrm{Ad} \beta \mathrm{gal}$-infected cells. Infection with Adref-1 resulted in a significant and dose-dependent inhibition of basal, and $\mathrm{H} / \mathrm{R}$-induced $\mathrm{NF}-\kappa \mathrm{B}$ transcriptional activity.

The findings from the transcriptional reporter assay were confirmed with an electrophoretic mobility shift assay (Figure $4 \mathrm{~B}$ ). $\mathrm{H} / \mathrm{R}$ led to an increase in NF- $\kappa \mathrm{B}$ DNA binding activity in control $\mathrm{Ad} \beta$ gal-infected cells. In comparison, cells infected with Adref-1 showed significant suppression of

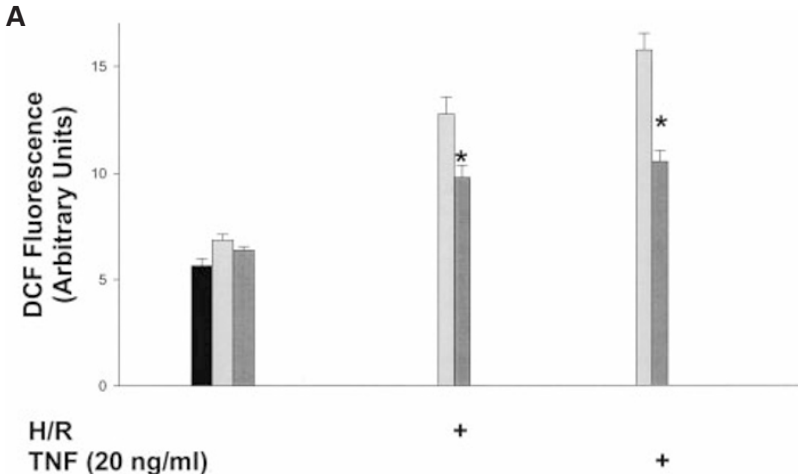

TNF $(20 \mathrm{ng} / \mathrm{ml})+$

Uninfected

Ad $\beta$ gal $200 \mathrm{MOI}$

AdRef-1 $200 \mathrm{MOI}$

B

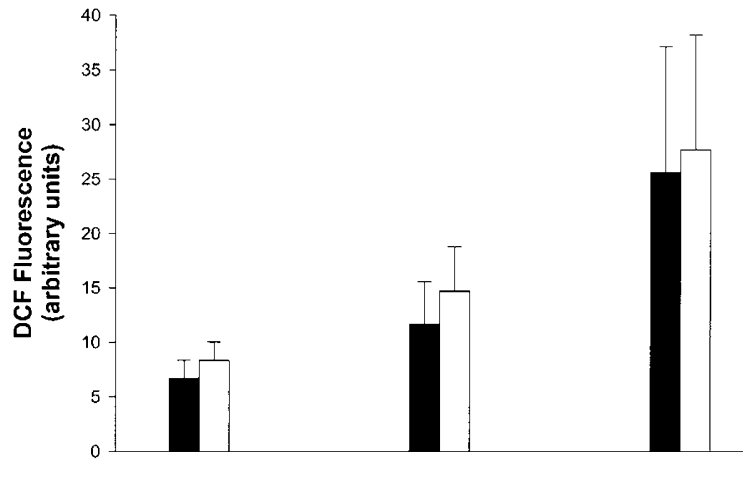

$\mathrm{H}_{2} \mathrm{O}_{2}(\mu \mathrm{M})$

10

100

\section{Adßgal 200MOI}

AdRef-1 200MO

C
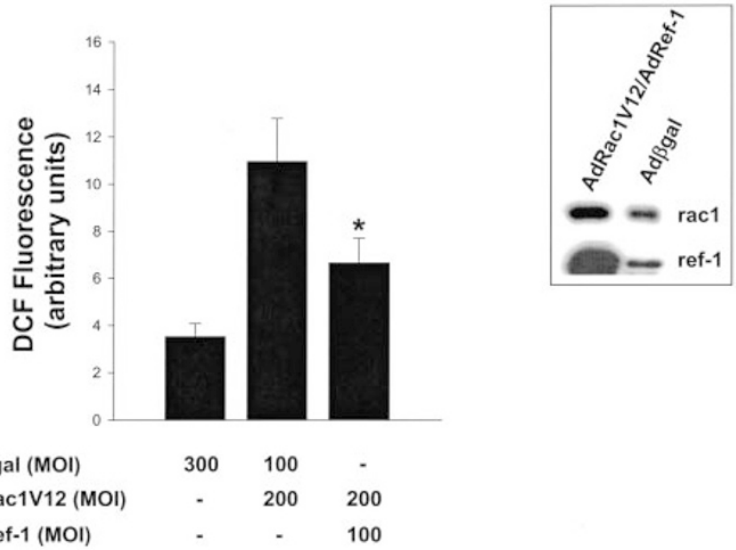

Figure 3 Ref-1 inhibits H/R-induced, and rac1-regulated oxidative stress. (A) Intracellular $\mathrm{H}_{2} \mathrm{O}_{2}$ levels in uninfected, Ad $\beta$ gal-, and Adref-1-infected cells, under normoxia, and with $\mathrm{H} / \mathrm{R}$ and TNF. ${ }^{*} P<0.05$ compared with $\mathrm{Ad} \beta$ gal. Reoxygenation was for $5 \mathrm{~min}$, and TNF $15 \mathrm{~min}$. (B) Intracellular $\mathrm{H}_{2} \mathrm{O}_{2}$ levels 5 min after addition of exogenous $\mathrm{H}_{2} \mathrm{O}_{2}$ in $\mathrm{Ad} \beta$ gal-, and Adref-1-infected cells. (C) Intracellular $\mathrm{H}_{2} \mathrm{O}_{2}$ levels in cells co-infected with Ad $\beta$ gal-, Adrac1V12-, and Adref-1. Inset shows adenoviral-induced co-overexpression of ref-1 and rac1V12. The figures are representative of two separate experiments 
A

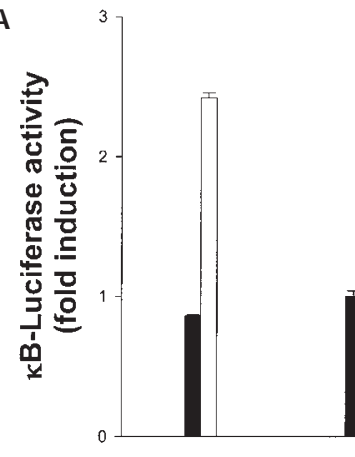

Uninfected

Adßgal (MOI)

AdRef-1 (MOI)

Normoxia

$\square \mathrm{H} / \mathrm{R}$
200

B

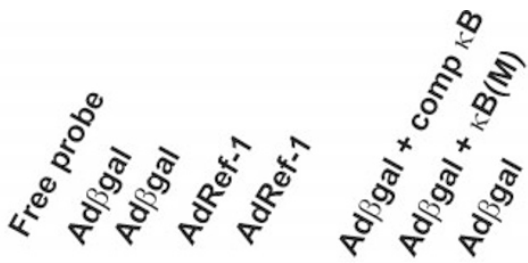

H/R

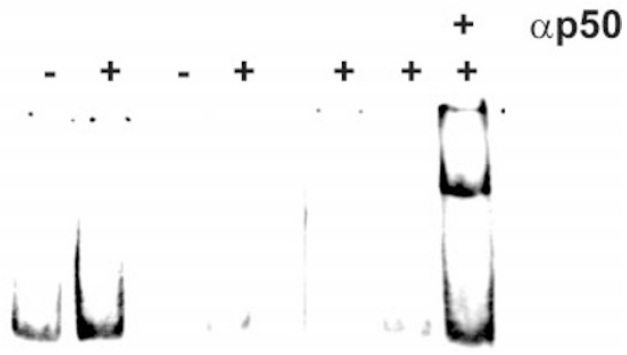

D

H/R

C
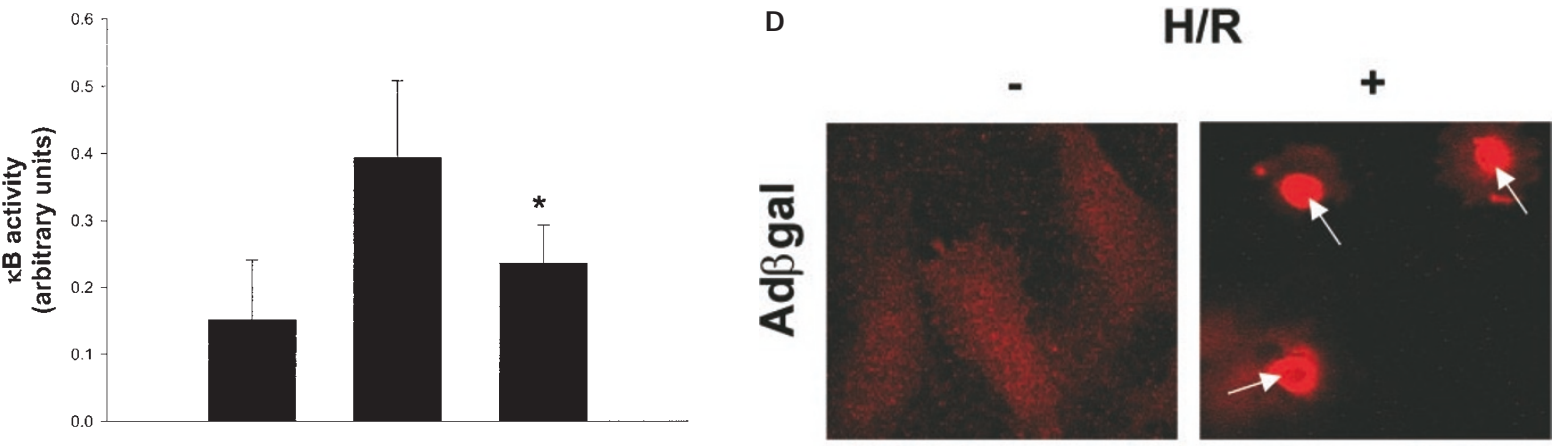

Adßgal (MOI)

AdRac1V12 (MOI)

300

100

AdRef-1 (MOI)

200

100
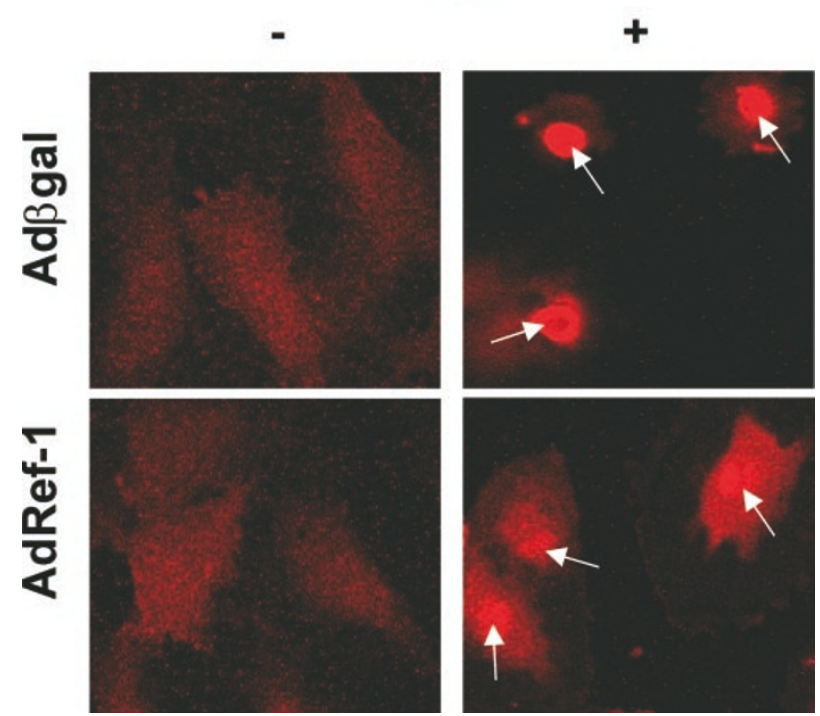

E

\section{H/R}
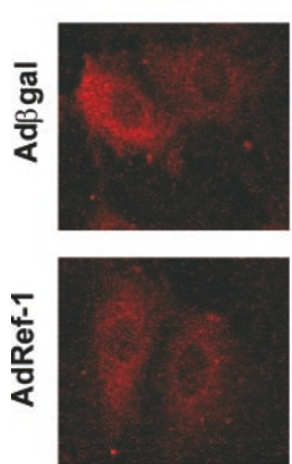

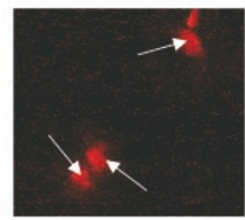

$\mathrm{H}_{2} \mathrm{O}_{2}(100 \mu \mathrm{M})$
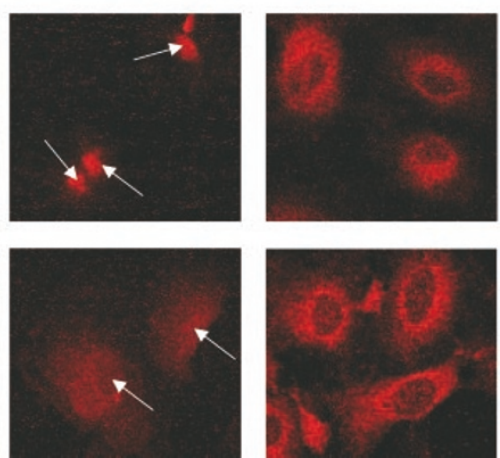

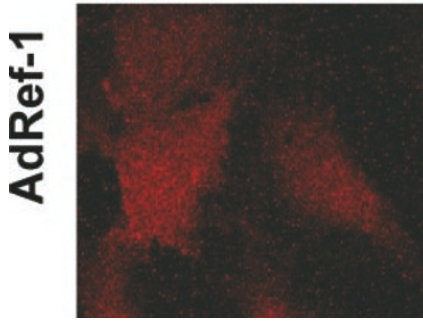

Figure 4 Ref-1 inhibits $\mathrm{H} / \mathrm{R}$-induced, rac1-regulated NF- $\kappa$ B activity by inhibiting its nuclear translocation. (A) NF- $\kappa$ B transcriptional activity measured by reporter assay in uninfected, $A d \beta$ gal-, and Adref-1-infected cells. Values are expressed as fold induction compared with $A d \beta$ gal-infected cells. ${ }^{*} P<0.05$ compared with $\mathrm{Ad} \beta \mathrm{g}$ al. The data is representative of three separate experiments. (B) EMSA for NF- $\kappa$ B DNA binding in Ad $\beta$ gal-, and Adref-1-infected cells. Where indicated, $100 \times$ excess unlabelled $\kappa \mathrm{B}$ oligonucleotide (comp $\kappa \mathrm{B})$, mutant $\kappa \mathrm{B}$ oligonucleotide $(\kappa \mathrm{B}(\mathrm{M}))$, or antibody to the p50 subunit of NF- $\kappa \mathrm{B}(\alpha \mathrm{p} 50)$ were added to the binding mixture. The figure is representative of two separate experiments. (C) NF- $\kappa B$ reporter assay in cells co-infected with $A d \beta g a l-$, Adrac1V12-, and Adref-1. * $P<0.05$ compared with AdRac1v12/Ad $\beta$ gal. Immunostaining for the p50 (D) and p65 (E) subunits of NF- $k B$ in Ad $\beta$ gal-, and Adref-1-infected cells under normoxia (D,E), after $\mathrm{H} / \mathrm{R}(\boldsymbol{D}, \mathbf{E})$, and after exogenous $\mathrm{H}_{2} \mathrm{O}_{2}$ addition $(\mathbf{E})$. Reoxgenation and $\mathrm{H}_{2} \mathrm{O}_{2}$ treatment were for $1 \mathrm{~h}$. Arrows indicate nuclei. The figures are representative of two separate experiments 
both basal, and $\mathrm{H} / \mathrm{R}$-induced $\mathrm{NF}-\kappa \mathrm{B}$ DNA-binding activity. Supershift analysis demonstrated that the H/R-stimulated increase in DNA binding activity was primarily due to p50 subunit containing dimers. This shows that overexpression of ref- 1 inhibits $\mathrm{H} / \mathrm{R}$-induced $\mathrm{NF}-\kappa \mathrm{B}$ activation in endothelial cells.

Activation of rac1 in response to stimuli including cytokines and $\mathrm{I} / \mathrm{R}$ is essential for full induction of $\mathrm{NF}-\kappa \mathrm{B}$ transcriptional activity. ${ }^{16,26}$ We therefore also examined whether ref- 1 modulates $\mathrm{NF}-\kappa \mathrm{B}$ activation specifically induced by rac1 (Figure $4 \mathrm{C}$ ). Expression of the activated rac1V12 allele resulted in significant increase in $\mathrm{NF}-\kappa \mathrm{B}$ transcriptional activity that was partly abrogated overexpression of ref-1. This, taken together with the inhibitory effect of ref-1 on rac1-stimulated $\mathrm{H}_{2} \mathrm{O}_{2}$ production, further implies that ref- 1 specifically inhibits a component(s) of the rac1-regulated machinery that leads to oxidative stress and $\mathrm{NF}-\kappa \mathrm{B}$ activation.

We also determined the stage in NF- $\kappa \mathrm{B}$ activation affected by ref-1. Basal nuclear and cytoplasmic levels of the p50 and p65 subunits of NF- $\kappa \mathrm{B}$ and their re-distribution with $H / R$ were assessed by immunostaining (Figure $4 D, E$ ). $\mathrm{H} / \mathrm{R}$ led to nuclear translocation of both p50 and p65 in control Adßgal-infected cells. In contrast, overexpression of ref-1 suppressed the H/R-stimulated nuclear translocation of p50 and p65, when compared to Ad $\beta$ gal-infected cells. This suggests that ref- 1 inhibits the H/R-stimulated signaling mechanism(s) that leads to nuclear translocation of NF- $\kappa \mathrm{B}$.

Finally, we determined the effect of ref-1 overexpression on $\mathrm{H}_{2} \mathrm{O}_{2}$-stimulated $\mathrm{NF}-\kappa \mathrm{B}$ re-distribution (Figure $4 \mathrm{E}$ ). Unlike $\mathrm{H} / \mathrm{R}$, addition of exogenous $\mathrm{H}_{2} \mathrm{O}_{2}$ to endothelial cells did not lead to nuclear translocation of the p65 subunit. However, $\mathrm{H}_{2} \mathrm{O}_{2}$ did result in strong peri-nuclear localization. In comparison with control $\mathrm{Ad} \beta$ gal-infected cells, cells overexpressing ref- 1 did not show any difference in this $\mathrm{H}_{2} \mathrm{O}_{2}$-stimulated re-distribution of NF- $\kappa \mathrm{B}$. This shows that similar to its inability to inhibit exogenous $\mathrm{H}_{2} \mathrm{O}_{2}$ induced apoptosis, ref- 1 is also unable to affect cellular re-distribution of $\mathrm{NF}-\kappa \mathrm{B}$ in response to addition of exogenous $\mathrm{H}_{2} \mathrm{O}_{2}$.

\section{Discussion}

Reports to date have shown that nuclear ref- 1 operates via two mechanisms. Through its $\mathrm{N}$-terminus cysteine residues it modulates transcription by reduction of nuclear transcription factors, and its C-terminus functions as an AP endonuclease. In our efforts to examine the role of ref- 1 in endothelial cell apoptosis we uncovered that ref- 1 is also capable of inhibiting oxidative stress, most likely by modulating $\mathrm{H}_{2} \mathrm{O}_{2}$ production, a mechanism hitherto unappreciated. This conclusion is supported by the following findings: (1) overexpression of ref- 1 resulted in suppression of $\mathrm{H} / \mathrm{R}$ and TNF-stimulated, and rac1-induced rise in intracellular $\mathrm{H}_{2} \mathrm{O}_{2}$, and (2) overexpression of ref-1 did not affect the elimination of exogenously supplied $\mathrm{H}_{2} \mathrm{O}_{2}$.

The ability of ref- 1 to inhibit stimulus-induced oxidative stress provides an additional mechanism for its protective effect against various pro-apoptotic oxidative stimuli. However, it is also possible that the DNA repair and transcriptional-enhancing properties of ref-1 play a role in suppressing cell death. Regardless of the precise mechanism(s) through which ref-1 inhibits apoptosis, its ability to regulate the production of cytoplasmic $\mathrm{H}_{2} \mathrm{O}_{2}$ can only be explained by an extra-nuclear function.

Ref-1 was first isolated from nuclear fractions of HeLa cells. ${ }^{27}$ Although ref-1 does have a nuclear localizing signal at its $\mathrm{N}$-terminus, in vitro studies have also demonstrated localization to the cytoplasm. ${ }^{13}$ Moreover, numerous studies show that in vivo, ref-1 has a differential cellular and subcellular expression pattern ${ }^{28-31}$ suggesting a potential physiologic extra-nuclear role. Using an overexpression strategy we were able to uncover one such extra-nuclear function. In endothelial cells, the oxidative stimulus $\mathrm{H} / \mathrm{R}$ led to a shift in the sub-cellular distribution of ref-1. This re-distribution is in accordance with another report showing that exogenous $\mathrm{H}_{2} \mathrm{O}_{2}$ is a potent stimulus for cytoplasmic to nuclear translocation of ref- $1 .{ }^{32}$ In contrast, adenoviral-driven change in nuclear/cytoplasmic ref-1 under normoxia, and particularly after $H / R$, was associated with suppression of oxidative stress, and NF$\kappa \mathrm{B}$ translocation. It is worth pointing out that Adref- 1 did lead to a marked increase in nuclear ref-1. However, this did not translate to an increase in $\mathrm{H} / \mathrm{R}$-induced NF- $\kappa \mathrm{B}$ DNA binding or transcriptional activity. This is explained by the temporal sequence of NF- $\kappa \mathrm{B}$ activation. DNA binding and transcription occur after, and are dependent upon, nuclear translocation. In addition, although this report focuses on ref-1's regulation of oxidative stress as a mechanism for it's effect on NF- $\kappa \mathrm{B}$ activation, it is worth considering that cytoplasmic ref-1 may also, directly or indirectly, affect other steps in the NF- $\kappa$ B activation sequence such as the activity of $I_{\kappa} \mathrm{B}$ kinases, or binding affinity to $I_{\kappa} \mathrm{B}$.

Arguably, the most intriguing finding of this study is that ref- 1 suppresses rac1-induced oxidative stress and NF- $\kappa \mathrm{B}$ activation. It is important to emphasize that our data show a functional interaction between ref-1 and rac1, and do not suggest a direct association between these two proteins. Nonetheless, the observation that both TNF and H/Rinduced oxidative stress was inhibited by ref- 1 is also consistent with such a functional interaction, since both these oxidative stimuli lead to ROS production, at least partly through a rac1-regulated $\mathrm{NAD}(\mathrm{P}) \mathrm{H}$ oxidase. ${ }^{3,20}$ Importantly, all the components of this oxidase are expressed in endothelial cells. In this regard, it is noteworthy that ref-1 physically binds with thioredoxin (TRX), another redox-regulatory protein. ${ }^{33} \mathrm{TRX}$ is capable of binding to p40phox, a component of the phagocyte cytoplasmic NADPH oxidase, and critical thiol residues on $\mathrm{TRX}$ are necessary for this interaction. ${ }^{34}$ This raises the interesting possibility that cytoplasmic ref- 1 via its critical cysteines, alone or in concert with $\mathrm{TRX}$, may also modulate the activity, of one or more components of a rac1-regulated $\mathrm{NAD}(\mathrm{P}) \mathrm{H}$-dependent oxidase expressed in endothelial cells. However, it would also be fair to say that the effect of ref-1 in modulating rac1-regulated $\mathrm{H}_{2} \mathrm{O}_{2}$ production does not exclude other mechanisms by which it may inhibit cytoplasmic oxidative stress. Notably, emerging evidence suggests that ref- 1 is also localized to the mitochondria, ${ }^{35,36}$ a major site of production of $\mathrm{H}_{2} \mathrm{O}_{2}$ and other ROS 
that have been implicated in apoptosis. Furthermore, independent of oxidant production, extra-nuclear ref-1 may also participate in other important cellular functions and processes (reviewed $\mathrm{in}^{37-42}$ ).

Ref- 1 activates p53 to bind to DNA, ${ }^{10}$ and promotes the trans-activating and pro-apoptotic functions of $\mathrm{p} 53 .{ }^{43}$ At first, this seems to contradict our observation that it has a protective role in $\mathrm{H} / \mathrm{R}$-induced apoptosis. However, most in vitro and in vivo studies have shown that hypoxia, and $\mathrm{H} / \mathrm{R}$ induced apoptosis occur independent of p53 status. ${ }^{17,44}$ Moreover, prior studies examining the role of ref- 1 in apoptosis have not distinguished between cytoplasmic and nuclear expression. Thus the manner in which ref-1 modulates apoptotic death may depend on its cellular compartmentalization and be stimulus-specific.

$A$ recent report examined the role of ref- 1 in endothelial cell NF- $\kappa$ B activity and apoptosis. ${ }^{45}$ This report showed that total cellular ref- 1 decreased after severe (18 h) of hypoxia, and that overexpression of ref-1 (using a liposome-based transfection protocol) resulted in an increase in $\mathrm{NF}-\kappa \mathrm{B}$ activation, and suppression of and TNF/hypoxia-induced apoptosis. However, the subcellular distribution of exogenous and endogenous ref-1, with or without oxidative stimuli (hypoxia or TNF), was not examined by the authors. Nor did the authors attempt to determine whether the degree of ref1 down-regulation or overexpression correlates with the extent of oxidative stress resulting from TNF or hypoxia. Our novel observations that forced adenoviral-mediated overexpression of ref-1 leads to (1) suppression of oxidative stress, and (2) inhibition of NF- $\kappa \mathrm{B}$ activation add new insights into the role of ref- 1 in endothelial cell biology, and are in contradiction with the findings of the above-mentioned report. The different conclusions of the two studies may be a result of differences in methodological approaches to overexpression coupled with differences in the degree of scrutiny regarding the sub-cellular compartmentalization of ref- 1 in endothelial cells.

In summary, this report shows that ref-1 has an important function in suppressing intracellular oxidative stress and apoptosis in endothelial cells, through modulation of a rac1-regulated oxidase, implicating an extranuclear function of ref-1 (Figure 5). Similar observations in an animal model of hepatic ischemia/reperfusion injury (data not shown) suggest that this extra-nuclear function may not be limited to endothelial cells. Moreover, taken in conjunction with other reports, our data suggests a paradigm in which ref-1 plays dual and opposing roles in the regulation of $\mathrm{NF}-\kappa \mathrm{B}$ activation. Cytoplasmic ref-1, through the feedback mechanism resulting in decreased ROS $\left(\mathrm{H}_{2} \mathrm{O}_{2}\right)$ production, inhibits rac1-stimulated, redoxregulated nuclear translocation of $\mathrm{NF}-\kappa \mathrm{B}$. Once in the nucleus, by maintaining $\mathrm{NF}-\kappa \mathrm{B}$ in the reduced state, and thereby enhancing its ability to bind DNA, ref-1 promotes $\kappa \mathrm{B}$-driven transcription. Therefore levels of nuclear versus cytoplasmic ref-1, and the ability of the cell to regulate these levels in response to oxidative stimuli, may well determine its net effect on NF- $\kappa \mathrm{B}$ activity. Importantly, a similar dual function of $\mathrm{TRX}$ in NF- $\kappa \mathrm{B}$ and heat shock factor activation has been shown. ${ }^{46,47}$ Thus, such spatial and temporal regulation of transcription factor activity by redox proteins may represent a common theme in the cellular response to oxidative stimuli.

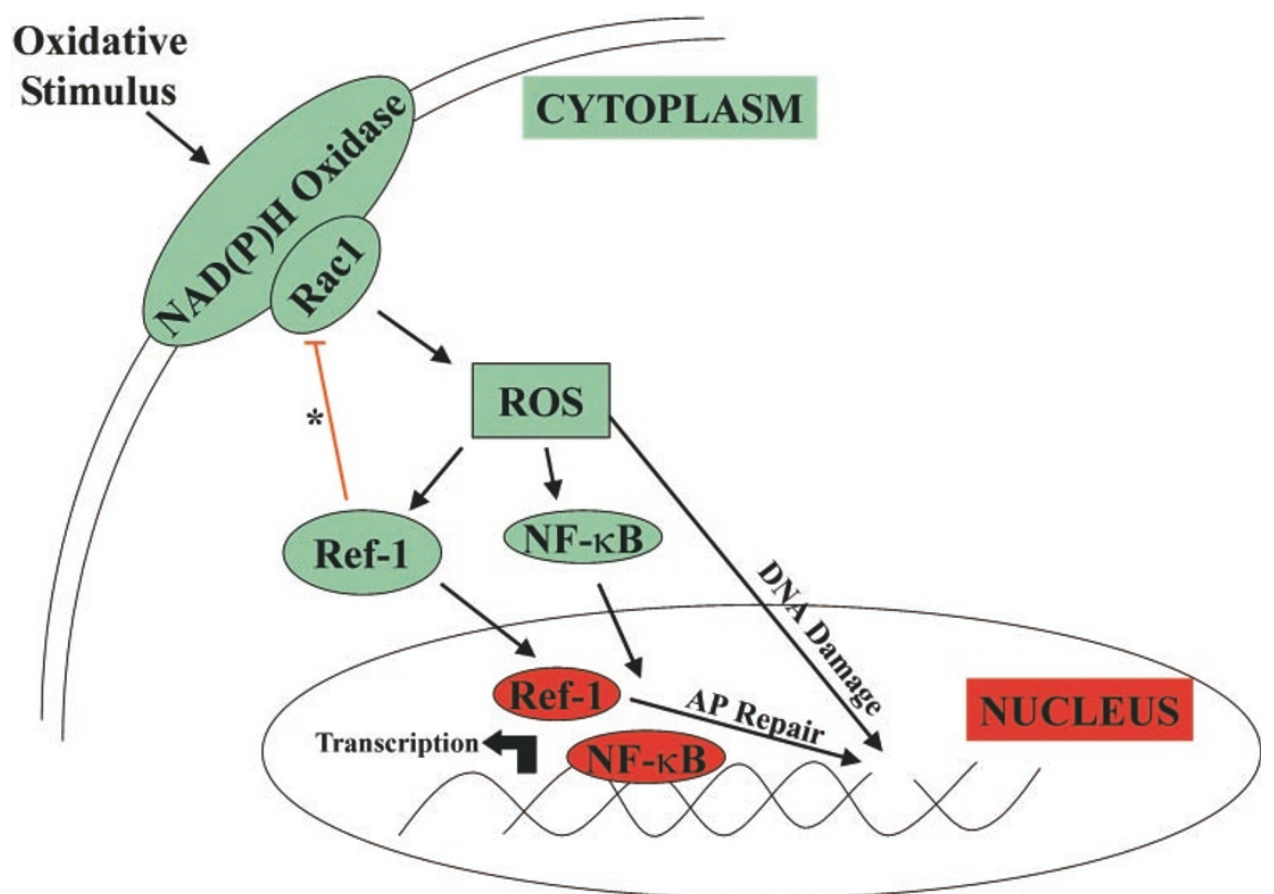

Figure 5 Nuclear and Cytoplasmic Roles of ref-1. Summary diagram illustrating the cytolasmic and nuclear effects of ref-1. *Signifies the role of ref- 1 in suppressing rac1-regulated ROS production demonstrated in this study. Figure does not include other potential mechanisms by which ref- 1 may suppress $\mathrm{NF}-\kappa \mathrm{B}$ activation, nor does it include other potential extra-nuclear actions of ref-1. AP: Apurinic/Apyrimidinic 


\section{Materials and Methods}

\section{Cell culture}

Human umbilical vein endothelial cells (HUVECs) were purchased from Clonetics (San Diego, CA, USA) and were grown and maintained in endothelial growth medium. Cells were passaged by standard trypsinization, and passages 2-7 were used in all experiments.

\section{Hypoxia/reoxygenation and quantification of apoptosis}

Hypoxia $(6 \mathrm{~h})$ and reoxygenation were attained as previously described $^{48}$ in a hypoxia chamber (Billups-Rothenberg, Inc., Del Mar, CA, USA). Apoptosis was quantified according to a previously described method ${ }^{3}$ using an ELISA that detects cytoplasmic histoneDNA fragments (Cell Death Detection ELISA, Boehringer Mannheim).

\section{Adenoviruses}

Recombinant replication-deficient adenoviruses were used in all experiments. Adref- 1 encoding the ref- 1 cDNA was constructed by homologous recombination in HEK293 cells. Ad $\beta$ gal, encoding the inert $E$. Coli lacZ gene, and Adrac1V12, encoding the constitutively active rac1 GTPase, have been described previously. ${ }^{3} \mathrm{Ad} \beta \mathrm{gal}$ infected cells, or uninfected cells were used as controls in all experiments. Recombinant adenoviruses were propagated, purified, and tittered, and HUVECs were infected at the specified multiplicity of infection (MOI) as previously described. ${ }^{3}$

\section{Western blotting and immunostaining}

Nuclear and cytoplasmic protein was extracted and fractionated as previously described. ${ }^{49}$ Western blots were performed with an antibody against ref-1 (SC-334, Santa Cruz Biotechnology), or rac1 (23A8, UBI) and bound immunocomplexes were visualized by enhanced chemiluminescence (Amersham). In some experiments, mouse monoclonal antibody against $\alpha$-tubulin (DM1A, Sigma) was used to confirm equal protein loading. Immunostaining employed primary antibodies against ref-1, p50 (SC-7178, Santa Cruz Biotechnology), or p65 (SC-372, Santa Cruz Biotechnology), and secondary fluorescein-tagged antibody that were used according to the manufacturer's recommendations. Images were captured on a Zeiss confocal laser-scanning microscope.

\section{Measurement of intracellular reactive oxygen species}

Intracellular $\mathrm{H}_{2} \mathrm{O}_{2}$ was detected with the peroxide-sensitive fluorophore $2^{\prime}, 7^{\prime}$-dichlorodihydrofluorescein diacetate (DCF-DA) as previously described. ${ }^{3}$ The fluorescence was measured after 5 min of incubation with DCF using excitation and emission wavelength of 488 and $515 \mathrm{~nm}$, respectively. Absolute fluorescence of 20-25 random cells was quantified with MetaMorph ${ }^{(i m}$ software. Values are mean \pm S.D.

\section{NF- $\kappa$ B reporter assay}

HUVECs were co-transfected with $1.5 \mu \mathrm{g}$ of a luciferase or CAT reporter plasmid containing three $\kappa \mathrm{B}$ binding sites, and $0.75 \mathrm{ug}$ of constitutive CAT or luciferase expression plasmid, using LipofectAMINE $^{\text {TM }}$ reagent (Life Technologies) according to the manufacturer $s$ instructions. After $16 \mathrm{~h}$ of reoxygenation luciferase and CAT activities in cell lysates were determined and normalized against each other to account for variations in transfection efficiency. All conditions were performed in triplicate and values are mean \pm S.D.

\section{Electrophoretic mobility shift assay (EMSA)}

EMSA for NF- $\kappa$ B DNA-binding activity $2 \mathrm{~h}$ after reoxygenation were carried out as previously described ${ }^{3}$ using a $\kappa B$ consensus sequence oligonucleotide ( $5^{\prime}$-AGT TGA GGG GAC TTT CCC AGGC-3'). In supershift experiments, antibody to p50 subunit was added to nuclear extracts for $30 \mathrm{~min}$ on ice prior to addition of labeled oligonucleotide.

\section{Statistical analysis}

Data are expressed as mean \pm S.D. Differences in measured variables between experimental and control groups were determined using a two-tailed paired $t$-test. $P<0.05$ was considered to be statistically significant.

\section{Acknowledgements}

This work was supported by a NIH grant P01 HL65608 (K Irani), the W.W. Smith Charitable Trust (K Irani), the American Heart Association (K Irani), the Bernard Foundation, the Abraham and Virginia Weiss Endowment, and a grant from the Cardio Fellows Foundation ( $P$ Angkeow). The authors wish to thank T Finkel, and T Curran for materials and advice.

\section{References}

1. Nakamura $\mathrm{H}$, Nakamura $\mathrm{K}$ and Yodoi $\mathrm{J}$ (1997) Redox regulation of cellular activation. Annu. Rev. Immunol. 15: 351-369

2. Gorlach A, Brandes RP, Nguyen K, Amidi M, Dehghani F and Busse R (2000) A gp91phox containing NADPH oxidase selectively expressed in endothelial cells is a major source of oxygen radical generation in the arterial wall [see comments]. Circ. Res. 87: 26-32

3. Deshpande SS, Angkeow P, Huang J, Ozaki M and Irani K (2000) Rac1 inhibits TNF-alpha-induced endothelial cell apoptosis: dual regulation by reactive oxygen species. FASEB J. 14: 1705-1714

4. Kim KS, Takeda K, Sethi R, Pracyk JB, Tanaka K, Zhou YF, Yu ZX, Ferrans VJ, Bruder JT, Kovesdi I, Irani K, Goldschmidt-Clermont P and Finkel T (1998) Protection from reoxygenation injury by inhibition of rac1. J. Clin. Invest. 101: $1821-1826$

5. Abate C, Patel L, Rauscher FJD and Curran T (1990) Redox regulation of fos and jun DNA-binding activity in vitro. Science 249: 1157-1161

6. Xanthoudakis S, Miao G, Wang F, Pan YC and Curran T (1992) Redox activation of Fos-Jun DNA binding activity is mediated by a DNA repair enzyme. EMBO J. 11: $3323-3335$

7. Walker LJ, Robson CN, Black E, Gillespie D and Hickson ID (1993) Identification of residues in the human DNA repair enzyme HAP1 (Ref-1) that are essential for redox regulation of Jun DNA binding. Mol. Cell. Biol. 13: 5370-5376

8. Huang RP and Adamson ED (1993) Characterization of the DNA-binding properties of the early growth response-1 (Egr-1) transcription factor: evidence for modulation by a redox mechanism. Dna And Cell Biology 12: 265-273

9. Huang LE, Arany Z, Livingston DM and Bunn HF (1996) Activation of hypoxiainducible transcription factor depends primarily upon redox-sensitive stabilization of its alpha subunit. J. Biol. Chem. 271: 32253-32259

10. Jayaraman L, Murthy KG, Zhu C, Curran T, Xanthoudakis S and Prives C (1997) Identification of redox/repair protein Ref-1 as a potent activator of p53. Genes Dev. 11: $558-570$

11. Mitomo K, Nakayama K, Fujimoto K, Sun X, Seki S and Yamamoto K (1994) Two different cellular redox systems regulate the DNA-binding activity of the p50 subunit of NF-kappa B in vitro. Gene 145: 197-203 
12. Tell G, Pellizzari L, Cimarosti D, Pucillo C and Damante G (1998) Ref-1 controls pax-8 DNA-binding activity. Biochem. Biophys. Res. Commun. 252: 178-183

13. Demple B, Herman T and Chen DS (1991) Cloning and expression of APE, the cDNA encoding the major human apurinic endonuclease: definition of a family of DNA repair enzymes. Proc. Natl. Acad. Sci. USA 88: 11450-11454

14. Walker LJ, Craig RB, Harris AL and Hickson ID (1994) A role for the human DNA repair enzyme HAP1 in cellular protection against DNA damaging agents and hypoxic stress. Nucleic Acids Res. 22: $4884-4889$

15. Walton M, Lawlor $P$, Sirimanne E, Williams $C$, Gluckman $P$ and Dragunow $M$ (1997) Loss of Ref-1 protein expression precedes DNA fragmentation in apoptotic neurons. Brain Res. Mol. Brain Res. 44: 167-170

16. Ozaki M, Deshpande SS, Angkeow P, Bellan J, Lowenstein CJ, Dinauer MC, Goldschmidt-Clermont PJ and Irani K (2000) Inhibition of the Rac1 GTPase protects against nonlethal ischemia/reperfusion-induced necrosis and apoptosis in vivo. FASEB J. 14: 418-429

17. Webster KA, Discher DJ, Kaiser S, Hernandez O, Sato B and Bishopric NH (1999) Hypoxia-activated apoptosis of cardiac myocytes requires reoxygenation or a pH shift and is independent of p53. J. Clin. Invest. 104: 239-252

18. Cho KS, Lee EH, Choi JS and Joo CK (1999) Reactive oxygen species-induced apoptosis and necrosis in bovine corneal endothelial cells. Invest Ophthalmol Vis. Sci. 40: $911-919$

19. Zulueta JJ, Sawhney R, Yu FS, Cote CC and Hassoun PM (1997) Intracellular generation of reactive oxygen species in endothelial cells exposed to anoxiareoxygenation. Am. J. Physiol. 272: L897-L902

20. Pracyk JB, Tanaka K, Hegland DD, Kim KS, Sethi R, Rovira II, Blazina DR, Lee L, Bruder JT, Kovesdi I, Goldschmidt-Clermont PJ, Irani K and Finkel T (1998) A requirement for the rac1 GTPase in the signal transduction pathway leading to cardiac myocyte hypertrophy. J. Clin. Invest. 102: 929-937

21. Muller JM, Rupec RA and Baeuerle PA (1997) Study of gene regulation by NFkappa B and AP-1 in response to reactive oxygen intermediates. Methods 11: $301-312$

22. Zwacka RM, Zhang Y, Zhou W, Halldorson J and EngelhardtJF (1998) Ischemia/ reperfusion injury in the liver of BALB/c mice activates AP-1 and nuclear factor kappaB independently of IkappaB degradation. Hepatology 28: 1022-1030

23. Zwacka RM, Zhou W, Zhang Y, Darby CJ, Dudus L, Halldorson J, Oberley L and Engelhardt JF (1998) Redox gene therapy for ischemia/reperfusion injury of the liver reduces AP1 and NF-kappaB activation. Nat. Med. 4:698-704

24. Imbert V, Rupec RA, Livolsi A, Pahl HL, Traenckner EB, Mueller-Dieckmann C, Farahifar D, Rossi B, Auberger P, Baeuerle PA and Peyron JF (1996) Tyrosine phosphorylation of I kappa B-alpha activates NF-kappa B without proteolytic degradation of I kappa B-alpha. Cell 86: 787-798

25. Schneider A, Martin-Villalba A, Weih F, Vogel J, Wirth T and Schwaninger M (1999) NF-kappaB is activated and promotes cell death in focal cerebral ischemia. Nat. Med. 5: 554-559

26. Sulciner DJ, Irani K, Yu ZX, Ferrans VJ, Goldschmidt-Clermont $P$ and Finkel T (1996) rac1 regulates a cytokine-stimulated, redox-dependent pathway necessary for NF-kappaB activation. Mol. Cell Biol. 16: 7115-7121

27. Xanthoudakis S and Curran T (1992) Identification and characterization of Ref-1, a nuclear protein that facilitates AP-1 DNA-binding activity. EMBO J. 11: 653665

28. Rivkees SA and Kelley MR (1994) Expression of a multifunctional DNA repair enzyme gene, apurinic/apyrimidinic endonuclease (APE; Ref-1) in the suprachiasmatic, supraoptic and paraventricular nuclei. Brain Res. 666: 137 142

29. Wilson TM, Rivkees SA, Deutsch WA and Kelley MR (1996) Differential expression of the apurinic/apyrimidinic endonuclease (APE/ref-1) multifunctional DNA base excision repair gene during fetal development and in adult rat brain and testis. Mutat Res. 362: 237-248

30. Kakolyris S, Kaklamanis L, Engels K, Fox SB, Taylor M, Hickson ID, Gatter KC and Harris AL (1998) Expression and subcellular localization of human AP endonuclease 1 (HAP1/Ref-1) protein: a basis for its role in human disease. Histopathology 33: 561-569
31. Duguid JR, Eble JN, Wilson TM and Kelley MR (1995) Differential cellular and subcellular expression of the human multifunctional apurinic/apyrimidinic endonuclease (APE/ref-1) DNA repair enzyme. Cancer Res. 55: 6097-6102

32. Tell G, Zecca A, Pellizzari L, Spessotto P, Colombatti A, Kelley MR, Damante G and Pucillo C (2000) An 'environment to nucleus' signaling system operates in $B$ lymphocytes: redox status modulates BSAP/Pax-5 activation through Ref-1 nuclear translocation. Nucleic Acids Res. 28: 1099-1105

33. Hirota K, Matsui M, Iwata S, Nishiyama A, Mori K and Yodoi J (1997) AP-1 transcriptional activity is regulated by a direct association between thioredoxin and Ref-1. Proc. Natl. Acad. Sci. USA 94: 3633-3638

34. Nishiyama A, Ohno T, Iwata S, Matsui M, Hirota K, Masutani H, Nakamura Hand Yodoi J (1999) Demonstration of the interaction of thioredoxin with p40phox, a phagocyte oxidase component, using a yeast two-hybrid system. Immunol. Lett. 68: $155-159$

35. Tell G, Crivellato E, Pines A, Paron I, Pucillo C, Manzini G, Bandiera A, Kelley MR, Di Loreto C and Damante G (2001) Mitochondrial localization of APE/Ref-1 in thyroid cells. Mutat. Res. 485: 143-152

36. Fung $\mathrm{H}$, Kow $\mathrm{YW}$, Van Houten B, Taatjes DJ, Hatahet $Z$, Janssen $Y M$, Vacek $P$ Faux SP and Mossman BT (1998) Asbestos increases mammalian AP endonuclease gene expression, protein levels, and enzyme activity in mesothelial cells. Cancer Res. 58: 189-194

37. Wilson III DM and Barsky D (2001) The major human abasic endonuclease: formation, consequences and repair of abasic lesions in DNA. Mutat Res. 485: $283-307$

38. Chiarini LB and Linden R (2000) Tissue biology of apoptosis. Ref-1 and cell differentiation in the developing retina. Ann. NY Acad. Sci. 926: 64-78

39. Fritz G (2000) Human APE/Ref-1 protein. Int. J. Biochem. Cell Biol. 32: 925 - 929

40. Evans AR, Limp-Foster M and Kelley MR (2000) Going APE over ref-1. Mutat. Res. 461: 83-108

41. Arner ES and Holmgren A (2000) Physiological functions of thioredoxin and thioredoxin reductase. Eur. J. Biochem. 267: 6102-6109

42. Mol CD, Hosfield DJ and Tainer JA (2000) Abasic site recognition by two apurinic/ apyrimidinic endonuclease families in DNA base excision repair: the $3^{\prime}$ ends justify the means. Mutat. Res. 460: 211-229

43. Gaiddon C, Moorthy NC and Prives C (1999) Ref-1 regulates the transactivation and pro-apoptotic functions of p53 in vivo. EMBO J. 18: 5609-5621

44. BialikS, Geenen DL, Sasson IE, Cheng R, Horner JW, Evans SM, Lord EM, Koch CJ and Kitsis RN (1997) Myocyte apoptosis during acute myocardial infarction in the mouse localizes to hypoxic regions but occurs independently of p53. J. Clin Invest. 100: 1363-1372

45. Hall JL, Wang X, Van A, Zhao Y and Gibbons GH (2001) Overexpression of Ref- 1 inhibits hypoxia and tumor necrosis factor-induced endothelial cell apoptosis through nuclear factor-kappab-independent and -dependent pathways. Circ. Res. 88: 1247-1253

46. Hirota K, Murata M, Sachi Y, Nakamura H, Takeuchi J, Mori K and Yodoi J (1999) Distinct roles of thioredoxin in the cytoplasm and in the nucleus. A two-step mechanism of redox regulation of transcription factor NF-kappaB. J. Biol. Chem. 274: $27891-27897$

47. Jacquier-Sarlin MR and Polla BS (1996) Dual regulation of heat-shock transcription factor (HSF) activation and DNA-binding activity by $\mathrm{H} 2 \mathrm{O} 2$ : role of thioredoxin. Biochem. J. 318: 187-193

48. Ozaki M, Deshpande SS, Angkeow P, Suzuki S and Irani K (2000) Rac1 regulates stress-induced, redox-dependent heat shock factor activation. J. Biol. Chem. 275: $35377-35383$

49. Andrews NC and Faller DV (1991) A rapid micropreparation technique fo extraction of DNA-binding proteins from limiting numbers of mammalian cells. Nucleic Acids Res. 19: 2499 